\title{
Methacrylic Acid as Chemical Treatment on the Properties of Kapok Husk Filled Linear Low Density Polyethylene Eco-Composites
}

\author{
Nurul Fatin Syazwani Arshad ${ }^{1, *}$, Salmah Husseinsyah ${ }^{1}$, and Lim Bee Ying ${ }^{1}$ \\ ${ }^{1}$ School of Materials Engineering, Universiti Malaysia Perlis, Taman Muhibah 02600 Arau, Perlis, \\ Malaysia.
}

\begin{abstract}
The effect of methacrylic acid (MAA) as chemical treatment on the properties of kapok husk $(\mathrm{KH})$ filled linear low density polyethylene (LLDPE) has been studied. KH, as natural filler was added into LLDPE by using Brabender Plasticizer EC plus at temperature $160^{\circ} \mathrm{C}$. The addition of $\mathrm{KH}$ content decreased the tensile strength and elongation at break of the eco-composites, but modulus of elasticity increased. Crystallinity of LLDPE/KH eco-composites decreased with increasing of $\mathrm{KH}$ content. Chemical treatment by MAA altered the tensile properties and crystallinity of eco-composites. The treated LLDPE/KH eco-composites showed higher tensile strength, modulus of elasticity and crystallinity of eco-composites due to better interfacial interaction between LLDPE matrix and KH filler. This has proven by Scanning Electron Microscopic (SEM).
\end{abstract}

\section{Introduction}

Polymer eco-composites have become more attractive in either research field or industries field recently [1]. These phenomena occurred due to high market price of neat polymer over polymer eco-composites and environmental awareness. The using of natural fillers increasing importance compared to synthetic filler. Many researchers studied the effect of natural filler filled polymer eco-composites nowadays $[2,3,4]$. This is driven by processing of natural filler is much easier compared to synthetic filler instead of economic.

Linear low density polyethylene matrix has been used in many applications such as food packaging, grocery bags, and kitchen utensils [5]. Partly due to LLDPE is cheaper compare to other polyethylene types. LLDPE has significant number of short branches which enable its chains to slide against each other without being entangled upon elongation at break and this gives LLDPE has high tensile strength and high impact and puncture resistance. Due to increasing demands on the LLDPE, a few researchers have studied the incorporation of natural filler filled LLDPE eco-composites $[6,7,8,9]$. However, kapok husk filled LLDPE is a new studied broad for polymer eco-composites field. $\mathrm{KH}$ is one of the agriculture wastes in Malaysia which produced around 0.008 million tonnes annually of kapok product such as mattress, pillow, and clothes [10]. This waste could be reinforcing

\footnotetext{
${ }^{*}$ Corresponding author: fatinsyaz13@gmail.com
} 
materials. The utilization does not only economic and abundance, it also will contribute to the waste disposal management as well to overcome the environmental problem.

However, the only disadvantage of polymer eco-composites is incompatibility between natural filler and polymer matrix which results in poor properties of the eco-composites. This encourages researchers to modify the properties of dispersion of natural filler into polymer matrix $[11,12,13,14]$. This is due to the reducing the hydrophilicity of natural filler by chemical treatments. In present work, LLDPE/KH eco-composites were developed and methacrylic acid (MAA) was used as chemical treatment towards $\mathrm{KH}$ to enhance the properties of the LLDPE/KH eco-composites. The effects of MAA on tensile properties, morphology and crystallinity of the LLDPE/KH eco-composites were studied.

\section{Experimental}

\subsection{Materials.}

Linear low density polyethylene (LLDPE) used as polymer matrix was supplied by PT Titan Petrokimia Nusantara, Indonesia with melt temperature $160^{\circ} \mathrm{C}$ and a density of $0.92 \mathrm{~g} / \mathrm{cm}^{3}$. The kapok husk $(\mathrm{KH})$ was obtained from Perlis, Malaysia. KH was cleaned and oven dried at $80{ }^{\circ} \mathrm{C}$ for 24 hours. Then, $\mathrm{KH}$ was crushed and grinded to become powder. The average particles size of KH was $63 \mu \mathrm{m}$ as determined by using Malvern Particle size analyser Instrument. MAA and ethanol was supplied by Sigma Aldrich (Penang, Malaysia).

\subsection{Filler treatment.}

MAA was dissolved in ethanol with amount of 3\% of $\mathrm{KH}$ filler. $\mathrm{KH}$ filler was added slowly into the solution and it was stirred for 2 hours at room temperature. The treated $\mathrm{KH}$ was soaked for 12 hours. After that, it was filtered and oven dried at $80{ }^{\circ} \mathrm{C}$ for 24 hours.

\subsection{Preparation of eco-composites samples.}

The LLDPE/KH eco-composites were prepared by Brabender Plasticizer EC Plus at temperature $160^{\circ} \mathrm{C}$. The total mixing LLDPE/ $\mathrm{KH}$ eco-composites according to formulation in Table 1 become homogenous was 7 minutes. After that, LLDPE/KH eco-composites were compressed by compression moulding machine GT-7014 A at temperature $160^{\circ} \mathrm{C}$. The $2 \mathrm{~mm}$ thickness sheet eco-composites were discharged. The samples were cut into dumbbell shapes by using Wallace Dumbbell Cutter.

Table 1. Formulation of untreated and treated LLDPE/KH eco-composites

\begin{tabular}{|c|c|c|}
\hline Materials & Untreated LLDPE/KH & Treated LLDPE/KH \\
\hline LLDPE & 100 & 100 \\
\hline KH (php) & $10,20,30,40$ & $10,20,30,40$ \\
\hline MAA (\%) & - & 3 \\
\hline
\end{tabular}

*php: part per hundred polymer 


\section{Characterization}

\subsection{Tensile test.}

Tensile test was conducted according to ASTM D638 by using Instron Machine Model 5569 with $30 \mathrm{~mm} / \mathrm{min}$ cross head speed. Tensile test were measured for 10 identical samples for each eco-composites. The tensile strength, elongation at break and modulus of elasticity were authorized by software.

\subsection{Morphological study.}

Morphological study of fractured surface of LLDPE/KH eco-composites was carried out by scanning electron microscopic with JEOL JSM-6460LA series. The samples were mounted on an aluminium stubs and sputter coated with a thin layer of palladium.

\subsection{Differential Scanning Calorimetric (DSC).}

The DSC analysis was conducted to study the melting and crystallization behaviour of LLDPE/KH eco-composites. The $10 \pm \mathrm{mg}$ samples of eco-composites were analyzed by using Perkin Elmer DSC-7 analyzer. Samples were heated from 20 to $250{ }^{\circ} \mathrm{C}$. The crystallinity $\left(\mathrm{X}_{\mathrm{c}}\right)$ of eco-composites was calculated using the following equations:

$$
\mathrm{X}_{\mathrm{c}}=\frac{\Delta \mathrm{H}_{\mathrm{f}}}{\Delta \mathrm{H}_{\mathrm{f}}^{\circ}} \times 100 \%
$$

Where $\Delta \mathrm{H}_{\mathrm{f}}$ is the heat fusion of LLDPE/KH eco-composites, $\Delta \mathrm{H}_{\mathrm{f}}^{\circ}$ heat fusion perfectly $(100 \%)$ crystalline LLDPE $\left(\Delta \mathrm{H}_{\mathrm{f}}^{\circ}=288 \mathrm{~J} / \mathrm{g}\right)$

\section{Results and discussion}

\subsection{Tensile properties.}

The effect of KH content on tensile strength of untreated and treated LLDPE/KH ecocomposites with MAA is shown in Fig. 1. The tensile strength of untreated eco-composites decreased with increasing of $\mathrm{KH}$ content. This is due to the incompatibility between LLDPE and KH. However, tensile strength of treated LLDPE/KH eco-composites improved compared to untreated eco-composites. It showed that the chemical treatment of $\mathrm{KH}$ by MAA promoted a better filler-matrix interfacial interaction due to the reduction of hydrophilic properties of KH filler. The highest improvement of treated LLDPE/KH ecocomposites compared untreated eco-composites is at 20 php with $67.5 \%$ increment. This was attributed to esterification reaction of MAA with hydroxyl groups of $\mathrm{KH}$. 


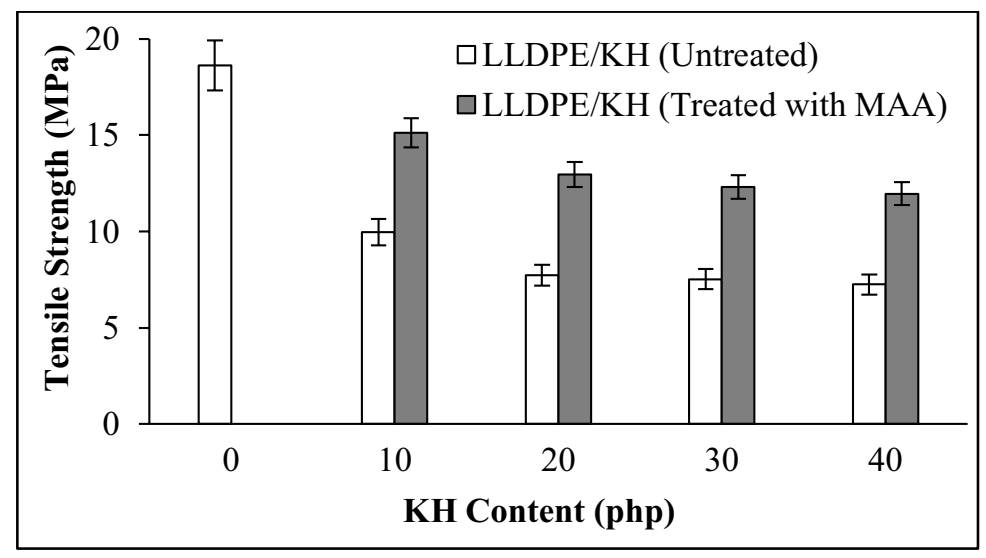

Fig. 1. Effet of KH content on tensile strength of untreated and treated LLDPE/KH eco-composites with MAA.

Fig. 2 demonstrates the effect of $\mathrm{KH}$ content on the elongation at break of untreated and treated LLDPE/KH eco-composites. The elongation at break of untreated eco-composites was decreased significantly with increasing of $\mathrm{KH}$ content. Nevertheless, treated LLDPE/KH eco-composites with MAA have lower elongation at break compared to untreated eco-composites. This is due to MAA treatment altered the $\mathrm{KH}$ filler by cooperating the $\mathrm{OH}$ group of $\mathrm{KH}$ and $\mathrm{OH}$ group of MAA. Thus, the treated eco-composites have better filler-matrix interaction and reduced the ductility of LLDPE/KH ecocomposites simultaneously. Both untreated and treated eco-composites were dramatically decreased at $10 \mathrm{php} \mathrm{KH}$ content compared to neat LLDPE. Meanwhile the largest drop of elongation at break was found at $20 \mathrm{php}$ treated eco-composites compared to untreated LLDPE/KH eco-composites.

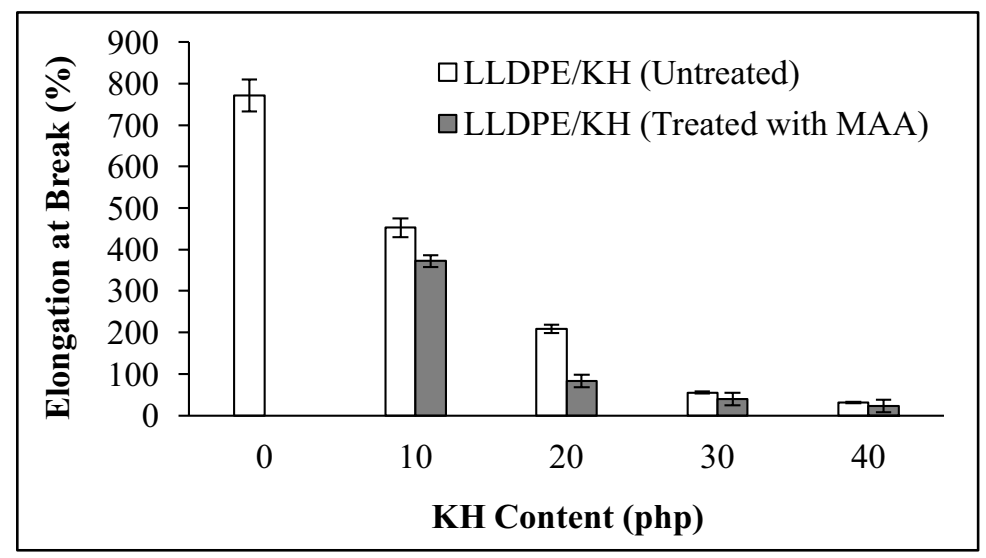

Fig. 2. Effect of KH content on elongation at break of untreated and treated LLDPE/KH ecocomposites with MAA.

Fig. 3 presents the effect of KH content on modulus of elasticity for both untreated and treated LLDPE/KH eco-composites. The untreated and treated eco-composites were increased in modulus of elasticity with the increasing of $\mathrm{KH}$ content. However, treated LLDPE/KH eco-composites by MAA indicated higher modulus of elasticity compared to untreated eco-composites. The highest increment was $49.2 \%$ for treated eco-composites as 
compared to untreated LLDPE/KH eco-composites at $20 \mathrm{php}$. This is because the presence of MAA had reduced the hydrophilicity of $\mathrm{KH}$ filler through esterification reaction by created covalent bond on between KH filler and MAA. Thus, this reduced the deformability of the LLDPE/KH eco-composites and indicated decreasing in stiffness.

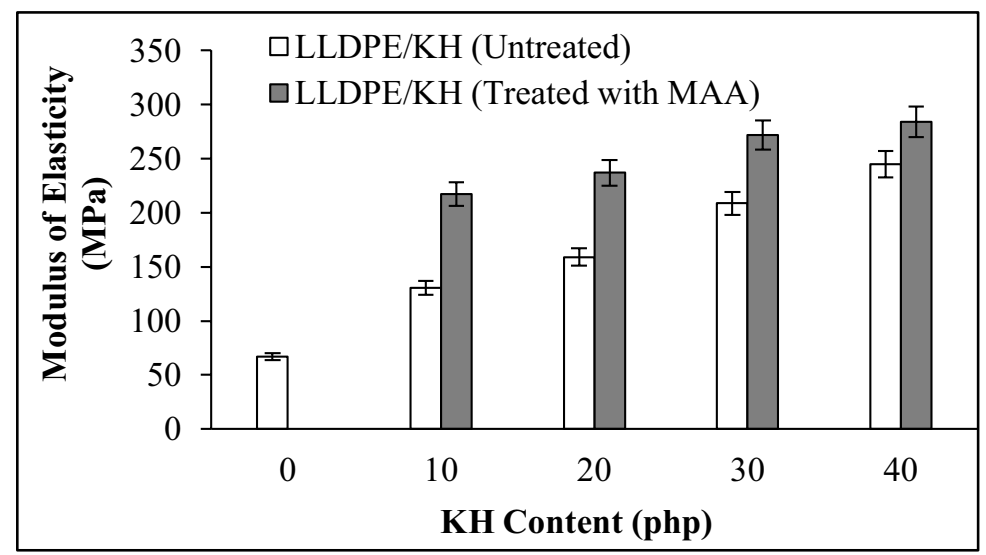

Fig. 3. Effect of KH content on modulus of elasticity of untreated and treated LLDPE/KH ecocomposites with MAA.

\subsection{Morphological study.}

Fig 4 illustrates the SEM micrograph of tensile fracture surface of untreated and treated LLDPE/KH eco-composites by using MAA at 20 and $40 \mathrm{php}$, respectively. From the micrographs figures, treated $\mathrm{KH}$ filler had better dispersion within LLDPE compared to untreated eco-composites due to presence of MAA treatment. This was expected since the tensile strength of MAA treated LLDPE/KH eco-composites was higher compared to untreated LLDPE/KH eco-composites as discussed in section 4.2.1. This strongly verified that the effect of MAA had improved the filler-matrix interfacial interaction of the ecocomposites.
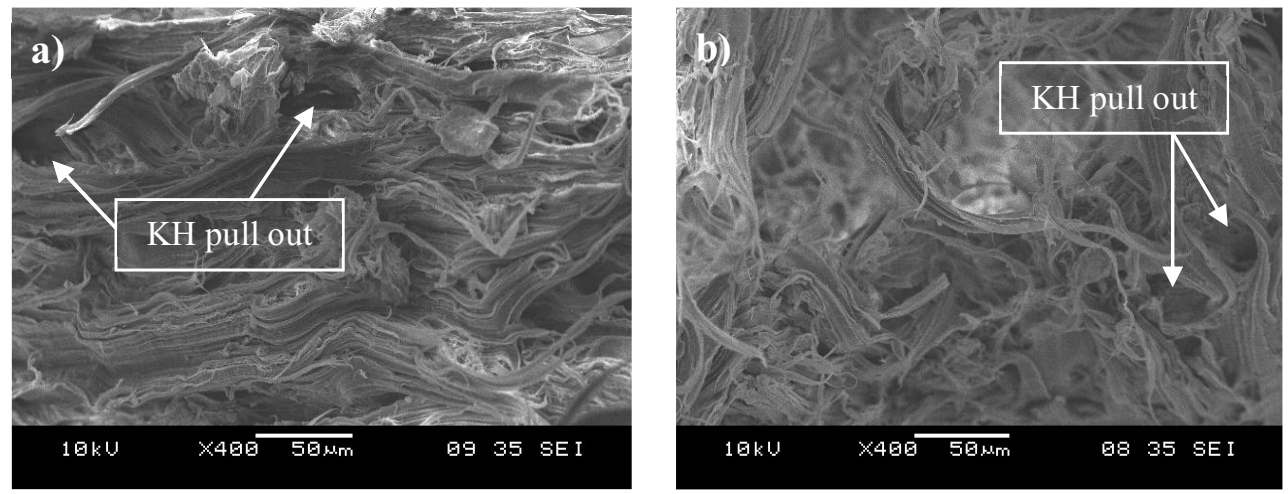

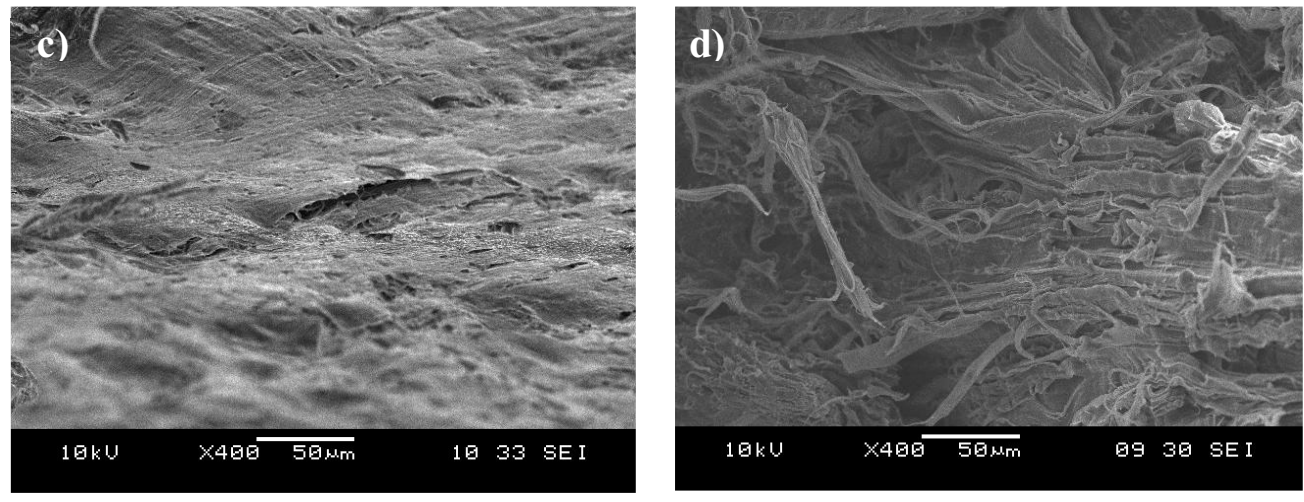

Fig. 4. SEM of tensile fracture surface: a) Untreated LLDPE/KH eco-composites at $20 \mathrm{php}$; b) Untreated LLDPE/KH eco-composites at $40 \mathrm{php}$; c) Treated LLDPE/KH eco-composites with MAA at $20 \mathrm{php} ; \mathrm{d})$ Treated LLDPE/KH eco-composites at $40 \mathrm{php}$.

\subsection{Differential Scanning Calorimetry (DSC).}

The DSC curve of the neat LLDPE, untreated and treated LLDPE/KH eco-composites with MAA at different $\mathrm{KH}$ content is illustrated in Fig. 5. Table 2 summarizes the DSC data for neat LLDPE, untreated and treated eco-composites. From the data, the $T_{m}$ does not show any significant changes within untreated and treated eco-composites at different filler content. Meanwhile, the crystallinity of LLDPE/KH eco-composites decreased with increasing of $\mathrm{KH}$ content. This is due to interruption of $\mathrm{KH}$ in crystalline growth of LLDPE. However, the treated LLDPE/KH eco-composites had higher $\mathrm{X}_{\mathrm{c}}$ compared to untreated eco-composites at similar $\mathrm{KH}$ content. This indicated that MAA was successfully attributed to the enhancement of the interfacial interaction between KH and LLDPE.

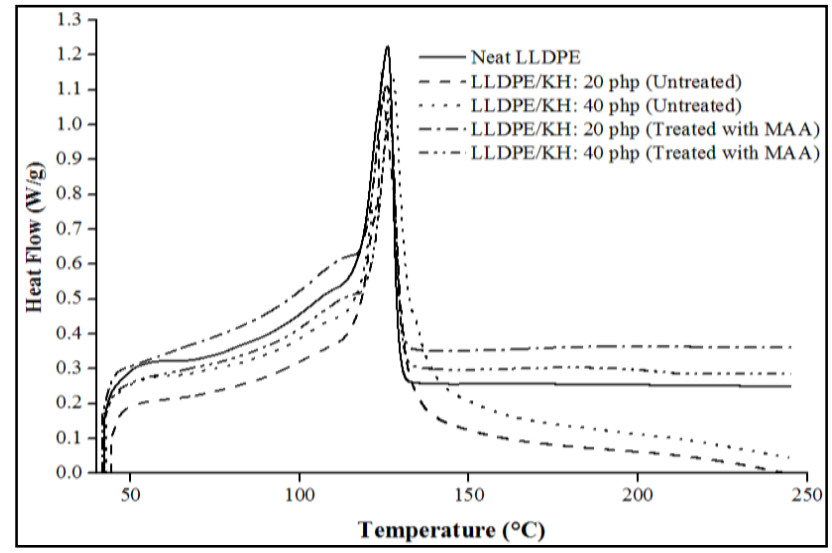

Fig. 5. DSC curves of neat LLDPE, untreated and treated LLDPE/KH eco-composites with MAA at different $\mathrm{KH}$ content. 
Table 2. DSC data of untreated and treated LLDPE/KH eco-composites with MAA.

\begin{tabular}{|l|c|c|c|}
\hline \multicolumn{1}{|c|}{ Materials } & $\mathbf{T}_{\mathbf{m}}\left({ }^{\circ} \mathbf{C}\right)$ & $\mathbf{\Delta H}_{\mathbf{f}}(\mathbf{J} / \mathbf{G})$ & $\mathbf{X}_{\mathbf{c}}$ \\
\hline Neat LLDPE & 126 & 82.6 & 28.9 \\
\hline LLDPE/KH: $20 \mathrm{php}$ & 128 & 60.1 & 20.9 \\
\hline LLDPE/KH: 40 php & 127 & 56.7 & 19.7 \\
\hline LLDPE/KH: $20 \mathrm{php}$ (Treated with MAA) & 126 & 76.7 & 26.6 \\
\hline LLDPE/KH: $40 \mathrm{php}$ (Treated with MAA) & 126 & 69.1 & 24.0 \\
\hline
\end{tabular}

\section{Conclusion}

The addition of $\mathrm{KH}$ had reduced the tensile strength, elongation at break and crystallinity of LLDPE/KH eco-composites. This was due to poor incompatibility of hydrophilic KH and hydrophobic LLDPE. However, treated LLDPE/KH with MAA has led to increasing of tensile strength and modulus of elasticity compared untreated eco-composites. The crystalline growth of eco-composites was improved after treated KH with MAA. This indicated that the treated $\mathrm{KH}$ with MAA was effective. The improvement of interfacial interaction of LLDPE and KH has been proven by SEM study.

\section{References}

1. N. Petchwattana, S. Covavisaruch, J. Bionic Eng., 10, 110 (2013)

2. H. Essabir, M.E. Achaby, E.M. Hilali, R. Bouhfid, A. Qaiss, J. Bionic Eng., 12, 129, (2015)

3. N. Sarifuddin, H. Ismail, Z. Ahmad, J. Phys. Sci., 24, 97 (2013)

4. F. Zhou, G. Cheng, B. Jiang, Appl. Surf. Sci., 292, 806 (2014)

5. S.C. Nwanonenyi, M.U. Obidiegwu, T.S. Onuchukwu, I.C. Egbuna, Int. J. Eng. Sci., 2, $42(2013)$

6. N.S.A. Wahab, M.F. Omar, H.M. Akil, N.N. Zulkepli, M.M.A.B. Abdullah, A.V. Sandu, Mater. Plas., 52, 1 (2016)

7. M. Sabetzadeh, R. Bagheri, M. Masoomi, Carbohydr. Polym., 119, 126 (2015)

8. M.A. AlMaadeed, Z. Nogellova, I. Janigova, I. Krupa, Mater. Des., 58, 209 (2014)

9. S. M. Mirmehdi, F. Zeinaly, F. Dabbagh, Composites Part B: Engineering, 56, 137 (2014)

10. FAO, Statistic of crop production in the world. Food Agric. Organiz. (2014)

11. R. Narendar, K.P. Dasan, Composites Part B: Engineering, 56, 770 (2014)

12. M.S.M. Rasidi, S. Husseinsyah, T.P. Leng, Bioresour. 9, 2033 (2014)

13. S. Husseinsyah, A. Ismail, H. Osman, Appl. Mech. Mater., 754, 187 (2015)

14. M.N.A. Lotfi, S. Husseinsyah, H. Osman, H. Ismail, Bioresour., 10, 3409 (2015) 